\title{
DRESS syndrome: A life-threatening complication of dapsone therapy
}

\author{
*Manori Nayanakantha Gamage ${ }^{1}$, Kanishka Thilakarathne ${ }^{2}$, Eranga Wicramanayake ${ }^{2}$, N M Marcellin ${ }^{2}$
}

Sri Lanka Journal of Child Health, 2019; 48(3): 261-262

DOI: http://dx.doi.org/10.4038/sljch.v48i3.

(Key words: DRESS syndrome, dapsone therapy)

\section{Introduction}

Drug Reaction with Eosinophilia and Systemic Symptoms (DRESS) syndrome is an idiosyncratic hypersensitive (type $1 \mathrm{~V}$ ) drug reaction which is associated with some groups of drugs ${ }^{1}$. Some of the commonly used drugs reported with DRESS syndrome (DS) are anticonvulsants, sulpha drugs, ACE inhibitors, antidepressants, beta blockers (atenolol) and some antibiotics ${ }^{2}$. The diagnosis DS is mainly clinical. Two panels of diagnostic criteria are described in $\mathrm{DS}^{1}$.

1. The RegiSCAR criteria for diagnosis of DS comprise the following: Fever $>38^{\circ} \mathrm{C}$, lymphadenopathy at a minimum of 2 sites, involvement of at least 1 internal organ and blood count abnormalities (lymphocytes above or below normal limits, eosinophils above laboratory limits, platelets below laboratory limits). Three out of the 4 criteria are required for diagnosis.

2. The Japanese group's criteria for diagnosis of $D S$ comprise the following: Maculopapular rash developing $>3$ weeks after starting suspected drug, prolonged clinical symptoms 2 weeks after discontinuation of the suspected drug, fever $>38^{\circ} \mathrm{C}$, liver abnormalities, leucocytosis $\quad\left(>11 \times 10^{9} / \mathrm{L}\right), \quad$ atypical lymphocytes $\quad(>5 \%), \quad$ eosinophilia $\left(>1.5 \times 10^{9} / \mathrm{L}\right)$, lymphadenopathy, leucocyte abnormalities and human herpes 6 reactivation. The diagnosis is confirmed by the presence of 7 criteria.

${ }^{1}$ Faculty of Medical Sciences University of Sri Jayawardenapura, Sri Lanka, ${ }^{2}$ Colombo South Teaching Hospital, Sri Lanka

*Correspondence: manorigamage@sjp.ac.lk

(iD)

orcid.org/ 0000-0003-3836-5945

(Received on 04 August 2017; Accepted after revision on 15 September 2017)

The authors declare that there are no conflicts of interest

Personal funding was used for the project.

Open Access Article published under the Creative

Commons Attribution CC-BY (c) (P)

\section{Case report}

An 11 year old girl was brought to the paediatric ward with a history of fever for 6 days and a generalized, erythematous, itchy, maculopapular rash and lip ulcers of 1 day duration. She also had dark yellow coloured urine and yellowish discolouration of the sclera for five days prior to admission. She was a diagnosed patient with lichen planus and was on dapsone $200 \mathrm{mg}$ daily for the last one month. With the onset of this febrile illness on the $3^{\text {rd }}$ day mother has withheld the dapsone therapy.

On examination, she was febrile $\left(>38^{\circ} \mathrm{C}\right)$, and ill looking. An intensely itchy, generalized erythematous macular papular rash was seen mainly over the trunk and both upper limbs. She was mildly icteric and was noted to have bilateral cervical lymphadenopathy. In addition, there were crusted lesions over the lips but the oral mucosa and vulval mucosa were normal. Her blood pressure was normal with normal pulse volume. There was hepatomegaly ( $2 \mathrm{~cm}$ below the right costal margin) but no splenomegaly.

Initial laboratory investigations revealed leucocytosis (white cell count $22 \times 10^{9} / \mathrm{L}$ ) associated with eosinophilia. (N 45\%, L 37\%, E 12\%). Platelet count was $335 \times 10^{9} / \mathrm{L}$ and there were atypical lymphocytes in the blood picture. There was evidence of hepatic involvement (alanine aminotransferase: $217 \quad \mathrm{IU} / \mathrm{L}, \quad$ aspartate aminotransferase: $122 \mathrm{IU} / \mathrm{L}$, total bilirubin 78 micromoles/L with the direct fraction 60.2 micromoles/L) but her urine analysis and renal functions were normal. Abdominal ultrasonography showed mild hepatomegaly with grade 1 fatty liver, with normal biliary tree. Portal venous system appeared normal. Tests for hepatitis A (anti-HAV IgM), hepatitis B (HBsAg), Epstein-Barr virus and cytomegalovirus were negative. Markers for auto immune hepatitis were also negative

Initially she was managed with antihistamines (chlorpheniramine) and antibiotics. As there was no improvement, a dermatological referral was made. Based on the clinical features, history and laboratory findings, a diagnosis of DS due to dapsone use was made. By that time dapsone was already withheld so she was started on oral prednisolone $1 \mathrm{mg} / \mathrm{kg} / \mathrm{day}$. With the commencement of prednisolone she improved dramatically. Other manifestations were managed symptomatically. She was discharged after 
completing a one week course of antibiotics with a plan to continue tapering oral prednisolone over 6 weeks.

\section{Discussion}

In 1996 Bocquot et al described a drug induced reaction presenting with high grade fever, generalized rash, lymphadenopathy, hepatic, renal, heart or lung involvement and eosinophilia. He termed it as Drug Reaction with Eosinophilia and Systemic Symptoms (DRESS) ${ }^{3}$. This is an idiosyncratic condition with a high mortality rate ${ }^{2}$. Commonest cause of death is liver failure ${ }^{2}$. The incidence of DS is 1 per 5,000 to 10,000 drug exposures $^{1}$. The pathogenesis of DRESS syndrome is not well understood, but the following are identified as possible factors ${ }^{2}$.

1. A genetic factor which alters immune response

2. A viral infection as a possible trigger

3. A defect in drug metabolism

Occurrence of DS has been reported with dapsone in published case series ${ }^{1,4}$. In our patient, the presence of fever $>38^{0} \mathrm{C}$, bilateral cervical lymphadenopathy, hepatic involvement and blood count abnormalities fulfilled the RegiSCAR criteria for diagnosis of DS. The presence of fever $>38^{\circ} \mathrm{C}$, maculopapular rash developing $>3$ weeks after starting dapsone, liver abnormalities, leucocytosis, atypical lymphocytes, eosinophilia and lymphadenopathy fulfilled the Japanese group's criteria for diagnosis of DS.

Management of DS involves early diagnosis with prompt discontinuation of the culprit drug, systemic steroids (prednisolone $1 \mathrm{mg} / \mathrm{kg}$ /day) and supportive care. During the course of drug therapy, gradual tapering of steroids over a period of more than one month is recommended. The French Society of Dermatology further recommends IVIG $(2 \mathrm{~g} / \mathrm{kg} /$ over 5 days) for patients with renal failure and respiratory failure $^{2}$. It has been reported that earlier the drug withdrawal, the better the prognosis. Other than steroids there are reported cases who have demonstrated beneficial effects of concomitant use of $\mathrm{N}$-acetyl cysteine ${ }^{5,6}$. Other management options found in the literature are plasmapheresis and cyclosporine therapy ${ }^{7,8}$. Clinicians who prescribe dapsone for different clinical conditions should have awareness about DS and its presentation.

\section{References}

1. Choudhary S, Mcleod M, Torchia D, Ramanelli P. Drug reaction with eosinophilia and systemic symptoms (DRESS) syndrome. The Journal of Clinical and Aesthetic Dermatology.2013; 6:31-7.

PMid: 23882307 PMCid: PMC3718748
2. Waseem D, Muzamil L, Najeebullah S, Imtiyaz D, Qayoom K, Farhat A, Pervez S. Dress syndrome: A review and update. Skin Disease and Skin Care 2016; 1:1.

3. Bocquet H, Boagot M, Roujeau JC. Drug induced pseudo-lymphoma and drug hypersensitivity (Drug rash with eosinophilia and systemic symptoms: (DRESS). Seminars in Cutaneous Medicine and Surgery 1996; 15:250-7. https://doi.org/10.1016/S10855629(96)80 038-1

4. Vinod KV, Arun K, Dutta K. Dapsone hypersensitivity syndrome: A rare life threatening complication of dapsone therapy. Journal of Pharmacology and Pharmacotherapeutics 2013; 4(2):158-60. https://doi.org/10.4103/0976500X.110917 PMid: 23761718 PMCid: PMC3669581

5. Afaf O, Wanis I, Izzat K, Nabeel A, Rania A. Sudden worsening of DRESS syndrome on tapering steroid dose with dramatic improvement on $\mathrm{N}$-acetylcysteine and steroid dose escalation. Ibnosina Journal of Medicine and Biomedical SciencesS. 2014; 6:101-5.

6. Moling O Tappeiner L, Piccin A, Pagai E Rossi P. Treatment of DIHS/DRESS syndrome with combined $\mathrm{N}$ acetylcysteine, prednisolone and valganciclovir - a hypothesis. Medical Science Monitor .2012; 18:57-62

https://doi.org/10.12659/MSM.883198

PMCid: PMC3560780

7. Thomas A, Edward I, Yara P, Daniel D, David P, et al. Severe DRESS syndrome managed with therapeutic plasma exchange. Paediatrics 2013; 131:3.

8. Harman KE, Morris SD, Higgins EM. Persistent anticonvulsant hypersensitivity syndrome responding to ciclosporin. Clinical and Experimental Dermatology 2003; 28:364-5.

https://doi.org/10.1046/j.13652230.2003.0 1267.x

PMid: 12823292 